\title{
La política administrativo-religiosa del estado visigodo en el Sureste: el caso de la creación de la sede episcopal Elotana
}

\author{
The visigothic' state administrative and religious policy \\ in the south east of the Iberian Peninsula: \\ the case of the Elotana episcopal seat
}

\author{
Jesús Peidro Blanes* \\ Centro Asociado de Elche - UNED
}

\begin{abstract}
RESUMEN
En el presente trabajo se analizan las actas de varios concilios eclesiásticos visigodos, con el objetivo de delimitar de forma más precisa los obispados de Vicentius de Begastri $y$ Sanabilis de Elo. $A$ partir del análisis cruzado de las listas episcopales contenidas en dichos concilios se lanza la hipótesis de la posible autoría de Witerico de las nuevas sedes y las implicaciones historiográficas derivadas de ello. Asimismo, se presenta un estado de la cuestión acerca de la ubicación de la sede elotana.

\section{PALABRAS CLAVE}

Concilio, obispado, visigodo, sede episcopal, Begastri, Elo.
\end{abstract}

ABSTRACT

In this paper we analyze the acts of several ecclesiastical councils of the visigothic period, with the purpose of delimiting the bishoprics of Vicentius of Begastri and Sanabilis of Elo. From the episcopal lists analysis, we hypothetisize of the Witeric's responsibility of these new seats and the historiographical implications derived. Also, we explain several theories about the location of the elotana seat.

\section{KEYWORDS}

Council, bishopric, visigothic, episcopal seat, Begastri, Elo.

\section{O. INTRODUCCIÓN}

En el contexto del enfrentamiento entre visigodos y bizantinos, en un momento que la investigación no ha logrado precisar más que entre finales del siglo VI y principios del siglo VII, se ha situado tradicionalmente la creación de dos nuevas

* C/ Alcázar de Toledo, 4, 2. ${ }^{\circ}$ izq., 03600 Elda (Alicante). Correo electrónico: jpeidro@ elx.uned.es 
sedes episcopales en el sureste peninsular por parte del Estado visigodo, la de Begastri y la de Elo. La probable ubicación de ésta última en el yacimiento de El Monastil es la que nos va a ocupar la mayor parte de este trabajo1.

El Monastil se encuentra situado en un meandro del río Vinalopó, en su curso medio, dominando una vía de paso desde la costa a la meseta que ha sido utilizada desde la Prehistoria (Fig. 1$)^{2}$.

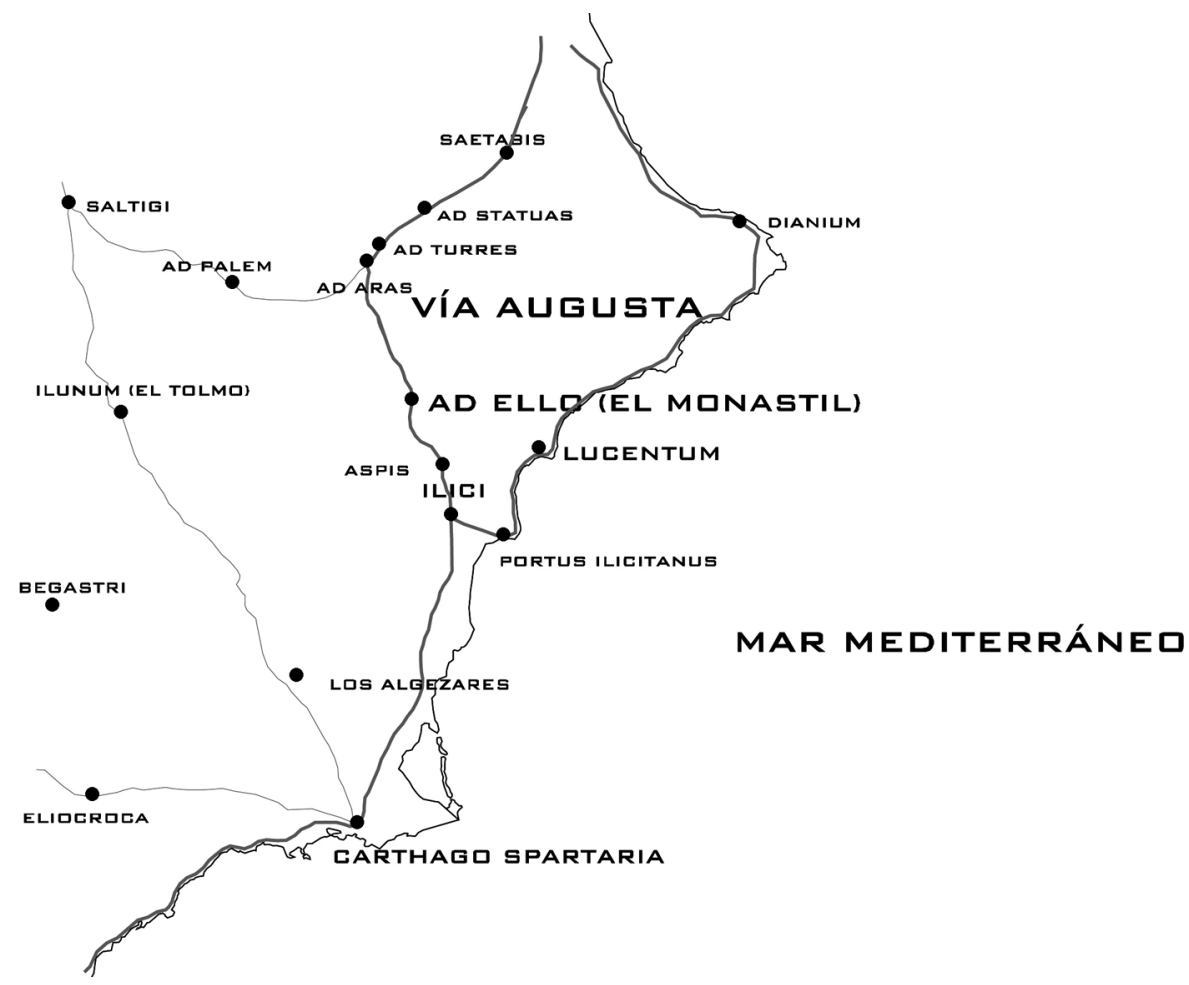

Fig. 1. Mapa de la Vía Augusta con la ubicación de la mansio Ad Ello.

1 Nuestras objeciones a la identificación de la sede elotana con el yacimiento albacetense de El Tolmo de Minateda se pueden consultar en un trabajo muy reciente PEIDRO BLANES, Jesús: «La región de la Oróspeda tras Leovigildo. Organización y administración del territorio», Verdolay, 11, 2008, pp. 263-276.

2 Para un amplio estado de la cuestión sobre la evolución histórica de El Monastil ver POVEDA NAVARRO, Antonio: El poblado ibero-romano de El Monastil. Introducción histórico-arqueológica, Elda, Ayuntamiento de Elda, 1988; Ibidem: «El Monastil: del oppidum ibérico a la civitas hispanorromana de Ello", Actas XXIII Congreso Nacional de Arqueología (Elche, 1995), vol. I, Elche, pp. 415-426. Acerca de la ubicación de Elo en El Monastil existe una abundante bibliografía. Uno de los primeros en situar la silla episcopal de Elo en Elda fue GAMS, Pius Bonifatius: Die Kirchengeschichte von Spanien, vol. II, Graz, 1862-1875 [1956]. Posteriormente otros autores han recogido esta identificación, desarrollándola con diversas argumentaciones, como es el caso de MATEU y LLOPIS, Felipe: «Sobre la identificación toponímica de Elota», Homenaje a Millás Vallicrosa, II, Barcelona, 1956, pp. 31-39, o de VIVES, José: Concilios Visigóticos e Hispanorromanos, CSIC, Madrid, 1963. Especialmente significativos son los trabajos de E. A. Llobregat y A. M. Poveda que la sitúan ya en el yacimiento de El Monastil aportando argumentos toponímicos, arqueológicos y de ubicación geográfica, LLOBREGAT CONESA, Enrique: «El Cristianisme primitiu 


\section{LAS ECCLESIA ELOTANA EN LAS FUENTES}

En el sínodo de Gundemaro aparece mencionado por primera vez un obispo de la ecclesiae Elotanae $e^{3}$. Han sido varios los autores que han visto en este elotanus (referido al obispo) el nombre de la ciudad de Elotat. Por su parte, E. A. Llo-

al País Valencià: una anàlisi d'Història local», Homenaje al Dr. Juan Reglà Campistol, vol. I, Valencia, 1975, pp. 19-27; Ibidem: La primitiva cristiandat valenciana, L'Estel, Valencia, 1977; Ibidem: «La antigua sede episcopal ilicitana y sus testimonios arqueológicos», Festa d'Elig. Homenaje a Pedro Ibarra Ruiz, Elche, 1978, pp. 23-28; Ibidem: «Las sedes episcopales valencianas preislámicas y su dependencia metropolitana. Subsidios para un análisis de la Ordinatio Ecclessiae Valentiae», Escritos del Vedat, X, 1980, pp. 397-413; Ibidem: «Relectura del Ravennate: dos calzadas, una mansión inexistente y otros datos de la geografía antigua del País Valenciano», Lucentum, 2, 1983, pp. 225-242; Ibidem: "Las épocas paleocristiana y visigoda", Arqueología del País Valenciano: panorama y perspectivas. Anejos de la revista Lucentum, 1985 pp. 383-414; Ibidem: «La provincia Cartaginense. Evolución y ciudades», Actas de las Jornadas «La Sede de Elo 1400 años de su fundación. El espacio religioso y profano en los territorios urbanos de occidente (siglo V-VII), Elda, 22-24 de abril de 1991, Elda, 1996, pp. 57-75; POVEDA NAVARRO, Antonio: El poblado ibero-romano..., p. 132 y ss.; Ibidem: «La Sede Episcopal Visigoda de Elo (Elda, Alicante)», Adellum, 2, 1988, pp. 20-28; Ibidem: «La creación de la sede de Elo en la expansión toledana de finales del s. VI en el SE. hispánico", Actas del XIV Centenario del III Concilio de Toledo (589-1989), Toledo, 1991, pp. 611-626; Ibidem: «Transformación y romanización del hábitat ibérico contestano de las cuencas alta y media del Vinalopó (provincia de Alicante). Del final de la República al Alto Imperio», Alebus, 1, 1991, pp. 65-78; Ibidem: «La estructura territorial en el Valle Medio del Vinalopó durante los ss. VVII», Alebus 2-3, 1992-1993, pp. 179-194; Ibidem: El Monastil: de oppidum ibérico..., p. 423; Ibidem: «El obispado de llici», en RIBERA i LACOMBA, Albert (ed.): Los orígenes del cristianismo en Valencia y su entorno, Valencia, 2000, pp. 85-92; Ibidem: «El obispado de Elo», en RIBERA i LACOMBA, Albert (ed.): Los orígenes del cristianismo en Valencia y su entorno, Valencia, 2000, pp. 93-99; Ibidem: «La iglesia paleocristiana de «El Monastil» (Elda, Alicante) en la Provincia Carthaginense (Hispania)», Hortus Artium Medievalium. Journal of the International Research Center for Late Antiquity and Middle Ages, vol. 9, ZagrebMotovun, pp. 113-125; MÁRQUEZ, Juan Carlos y POVEDA, Antonio: «Espacio religioso y cultura material en Elo (ss. IV-VII dC)», V Reunió d'Arqueologia Cristiana Hispànica, Cartagena (1998), 2000, Barcelona, pp. 177-184. Asimismo, otros autores se han hecho eco de esta hipótesis AZUAR RUIZ, Rafael: «Panorama de la arqueología medieval de los valles alto y medio del Vinalopó (Alicante)», Lucentum, II, Alicante, 1983, pp. 349-383; REYNOLDS, Paul: «Settlement and Pottery in the Vinalopó Valley (Alicante, Spain) A. D. 400-700", Tempus Reparatum, BAR International Series, 588, Oxford, 1993; VALLEJO GIRVÉS, Margarita: «Bizancio y la España tardoantigua (SS. V-VIII): Un capítulo de historia mediterránea», Memorias del Seminario de Historia Antigua, IV, Universidad de Alcalá, Alcalá de Henares, 1993; MÁRQUEZ VILLORA, Juan Carlos: «La cristianización preislámica de las comarcas alicantinas. Balance y estado de la cuestión», Actas de las Jornadas "La Sede de Elo 1400 años de su fundación. El espacio religioso y profano en los territorios urbanos de occidente (siglo V-VII), Elda, 22-24 de abril de 1991, 1996, pp. 375395; Ibidem: «Mesas polilobuladas de tradición oriental en la Península Ibérica: entre la religión y el comercio", V Reunió d'Arqueologia Cristiana Hispànica, Cartagena (1998), Barcelona, 2000, pp. 519-527; GARCÍA MORENO, Luis: Historia de España visigoda, Madrid, $1998^{2}$ (1 ${ }^{\mathrm{a}}$ ed. 1988); SEGURA, Gabriel y TORDERA, Francisco: «La necrópolis tardorromana del camino de El Monastil (Elda, Alicante): cristianismo y paganismo en la cuenca del río Vinalopó durante el siglo VI dC", V Reunió d'Arqueologia Cristiana Hispànica, Cartagena (1998), Barcelona, 2000, pp. 263-270. Recientemente se ha realizado un estado de la cuestión en PEIDRO BLANES, Jesús: «El valle de Elda, de los romanos al final de la Antigüedad», en AA.VV.: Elda. Arqueología y Museo. Ciclo Museos Municipales en el MARQ, Alicante, 2008, pp. 78-95.

3 MARTÍNEZ, Gonzalo. y RODRíGUEZ, Félix.: La Colección Canónica Hispana. VI. Concilios hispánicos: tercera parte, Madrid, 2002, p. 212, dan por buena esta lectura. Sin embargo, aportan otras diferentes en el caso de los concilios celebrados después del 610, que tendremos ocasión de analizar más adelante.

${ }_{4}$ Se trata de un error en el que a partir de los trabajos del P. Flórez han incurrido otros autores, FLÓREZ, Enrique: España Sagrada, Vol. VI, Madrid, 1751, pp. 217-223; MATEU y LLOPIS, Felipe: op. cit., pp. 31-39; GARCIA MORENO, Luis: La España..., p. 352. Parece evidente que, en todo caso, se trataría de la ciudad de Elo, y no de Elota, puesto que -tanus es un sufijo bien conocido en los concilios, apareciendo otros obispos con el nombre de saetabitanus (por Saetabi, y no por Saetabita), ilicitanus (por 
bregat, siguiendo la edición realizada por J. Vives, defendió esta lectura, sin tener en cuenta otras 5 . No obstante, la lectura elotanus no es uniforme en la tradición escrita de los concilios. Existen versiones en las que se lee ecclesia erotana, eiotana o incluso dotana lo que convertiría el nombre de la ciudad en Ero o Eio ${ }^{6}$.

Las variaciones en las lecturas que ofrecen las diferentes versiones son múltiples en los concilios del siglo VII, si bien en el caso de la Constitución de los obispos de la Cartaginense aparece la lectura Elotanae en el códice Emilianense, frente a llicitanae que recoge el Proceso Super ordinatione ecclesiae Valentinae, que en opinión de G. Martínez y F. Rodríguez podría deberse al día en el que el amanuense copiase el texto ${ }^{7}$ (Tabla 1).

Ilici y no por llicita), lo cual refuerza la idea de que -tanus hace referencia al gentilicio o, en este caso, a la sede a que pertenece el prelado. De este hecho ya se había advertido, FERNÁNDEZ GUERRA, Antonio: Deitania y su cátedra episcopal de Begastri, Madrid, 1879, p. 144, núm. 39, argumento sobre el que insistió E. A. Llobregat en su estudio sobre el primer cristianismo en tierras valencianas, seguido posteriormente por otros autores LLOBREGAT CONESA, Enrique: La primitiva cristiandat..., p. 94; POVEDA NAVARRO, Antonio: El poblado ibero-romano..., p. 132; Ibidem: La Sede Episcopal..., p. 20; GUTIÉRREZ, Sonia, ABAD, Lorenzo y GAMO, Blanca: «Eio, lyyuh y el Tolmo de Minateda (Hellín, Albacete): de sede episcopal a madina islámica», VI Reunió d'Arqueologia Cristiana Hispànica, Valencia, 2005, pp. 345-370.

5 LLOBREGAT CONESA, Enrique: El Cristianisme primitiu...; Ibidem: La primitiva cristiandat...; Ibidem: La antigua sede episcopal ilicitana...; Ibidem: Las sedes episcopales valencianas preislámicas...; Ibidem: Relectura del Ravennate...; Ibidem: Las épocas paleocristiana y visigoda... El propio E. A. Llobregat señaló la posibilidad de situar en El Monastil la ciudad de lyyuh/lyih, ver Ibidem: Teodomiro de Oriola, Diputación de Alicante, Alicante, 1973, especialmente en pp. 46-50; Ibidem: Las épocas paleocristiana y visigoda... No obstante, todo parece indicar que la ciudad de lyyuh/lyih debe relacionarse con El Tolmo de Minateda (Hellín, Albacete) ABAD, Lorenzo, GUTIÉRREZ, Sonia y GAMO, Blanca: La ciudad visigoda del Tolmo de Minateda...; Ibidem: La basílica y el baptisterio del Tolmo de Minateda...; GUTIÉRREZ LLORET, Sonia: La identificación de Madinat lyih...

6 El estudio clásico que hace referencia a la totalidad de los concilios de época visigoda es el de VIVES, José: op. cit., p. 409, en el que el autor toma como referencia un único manuscrito al tratar el sínodo de Gundemaro (concretamente el Vigiliano), obviando otras tradiciones escritas. El uso de una sola fuente condiciona la interpretación de J. Vives, que transcribe la lectura elotana. En este sentido se han pronunciado algunos investigadores, que creen más probable la lectura eiotana ABAD, Lorenzo y GUTIÉRREZ, Sonia: «lyih (El Tolmo de Minateda, Hellín, Albacete). Una ciuitas en el limes visigodo-bizantino», Antigüedad y Cristianismo, XIV, 1997, pp. 591-600; ABAD, Lorenzo, GUTIÉRREZ, Sonia y GAMO, Blanca: «La ciudad visigoda del Tolmo de Minateda (Hellín, Albacete) y la sede episcopal de Eio», en RIBERA i LACOMBA, Albert (ed.): Los orígenes del cristianismo en Valencia y su entorno, Valencia, 2000, pp. 101-112; Ibidem: «La basílica y el baptisterio del Tolmo de Minateda (Hellín, Albacete)», Archivo Español de Arqueología, 73, n. ${ }^{\circ}$ 181-182, CSIC, 2000, pp. 193-221; Ibidem: «El Tolmo de Minateda. Hellín (Albacete)», en AA.VV. (2004): Investigaciones Arqueológicas en Castilla-La Mancha, 19962002, Toledo, pp. 145-162; GUTIÉRREZ LLORET, Sonia: «La identificación de Madinat lyih y su relación con la sede episcopal Elotana. Nuevas perspectivas sobre viejos problemas", Scripta in Honorem Enrique A. Llobregat Conesa, Alicante, 2000, pp. 481-501; Ibidem: «llici en la Antigüedad Tardía. La ciudad evanescente», en AA.VV.: Iberia, Hispania, Spania. Una mirada desde Ilici, Alicante, 2004, pp. 95-110. Por fortuna, recientemente se han editado ediciones críticas de los concilios visigóticos del siglo VII, por lo que se han puesto a disposición de la investigación las diferentes lecturas recogidas en los manuscritos que incluyen las actas de los concilios de época visigoda, MARTíNEZ, Gonzalo y RODRÍGUEZ, Félix: La Colección Canónica Hispana. V. Concilios hispánicos: segunda parte, Madrid, 1992; Ibidem: La Colección Canónica Hispana. VI. Concilios hispánicos: tercera parte, Madrid, 2002.

7 MARTÍNEZ, Gonzalo y RODRÍGUEZ, Félix: La Colección Canónica Hispana. VI.., p. 48 y ss. En el Concilio XI de Toledo aparece ecclesiae Hilicitanae qui et Elotanae; en el concilio XII de Toledo encontramos diferentes variantes del topónimo, al igual que en el caso de la sede ilicitana, así recoge las lecturas ecclesiae Ilicitanae qui et Elotanae; Illicitan qui et lotan; Hilicitanae et Eiotane; llicitane qui et lothae; Hilicitane que et lotane; Elicita nectiotane; Hilicitane qui et Elotanae. Por su parte en los concilios XIII 
La política adminstrativo-religiosa del estado visigodo en el Sureste...

Tabla 1. Diferentes lecturas de la sede ilicitana y elotana contenidas en los concilios eclesiásticos ceelbrados en Toledo a lo largo del siglo VII.

\begin{tabular}{|l|l|l|l|l|l|}
\hline \multicolumn{5}{|c|}{ Diferentes lecturas contenidas en los concilios de Toledo (siglo VII) } \\
\hline $\begin{array}{l}\text { licitanae } \\
\text { qui et } \\
\text { Elotham }\end{array}$ & $\begin{array}{l}\text { Hilicitane } \\
\text { qui et } \\
\text { Eiotam }\end{array}$ & $\begin{array}{l}\text { Ilicitanae } \\
\text { quiete } \\
\text { Lotani }\end{array}$ & $\begin{array}{l}\text { Ilicitanae } \\
\text { quiete } \\
\text { lothani }\end{array}$ & $\begin{array}{l}\text { Ilicitanae } \\
\text { qui et } \\
\text { Eiotanae }\end{array}$ & $\begin{array}{l}\text { Ilicitanae } \\
\text { quiete } \\
\text { lotani }\end{array}$ \\
\hline $\begin{array}{l}\text { Ilicitanae } \\
\text { quiete } \\
\text { Ilotani }\end{array}$ & $\begin{array}{l}\text { Hilicitanae } \\
\text { qui et } \\
\text { Elotanae }\end{array}$ & $\begin{array}{l}\text { Hilicitanae } \\
\text { qui et } \\
\text { lotanae }\end{array}$ & $\begin{array}{l}\text { Hilicitanae } \\
\text { qui et } \\
\text { Eiotanae }\end{array}$ & $\begin{array}{l}\text { Ilicitanae } \\
\text { qui et } \\
\text { Elotanae }\end{array}$ & $\begin{array}{l}\text { Illicitan } \\
\text { qui et } \\
\text { lotan }\end{array}$ \\
\hline $\begin{array}{l}\text { Hilicitanae } \\
\text { et Eiotane }\end{array}$ & $\begin{array}{l}\text { Ilicitane } \\
\text { qui et } \\
\text { lothae }\end{array}$ & $\begin{array}{l}\text { Hilicitane } \\
\text { que et } \\
\text { lotane }\end{array}$ & $\begin{array}{l}\text { Elicita } \\
\text { nectiotane }\end{array}$ & $\begin{array}{l}\text { Elicitanae } \\
\text { qui et } \\
\text { Dotanae } \\
\text { sedis }\end{array}$ & $\begin{array}{l}\text { Hilicitanae } \\
\text { qui et } \\
\text { Dotanae }\end{array}$ \\
\hline
\end{tabular}

(Fuente: Martínez, Gonzalo y Rodríguez, Félix: La Colección Canónica Hispana, vols. V y VI, CSIC, Madrid).

\subsection{El topónimo: ¿Elo/Eio/Ero?}

En este punto, resulta necesario aclarar la identificación del topónimo Elo/Eio/Ero. Las lecturas erotanae o dotanae deberían tomarse con mucha cautela si no eliminarse del debate, dado que no parecen ser transcripciones correctas $^{8}$. Debemos valorar, por tanto, que se trate de elotanae o bien de eiotanae. La lectura más comúnmente aceptada, como hemos comentado anteriormente es elotanus, esto es, de Elo. Los argumentos utilizados para situar el lugar de Elo en El Monastil se basan, en primer lugar en la toponimia de época romana. E. A. Llobregat propuso la siguiente evolución del topónimo: Ello/Elo/Ella/Ecla/Etla/Elda9 . La identificación de El Monastil con la ciudad de lyyuh/lyyih no es correcta, de manera que el paso toponímico de Elo a lyyu(h)/lyyih no debe contemplarse como tal. Es más, si el paso de Ello a Elo no resulta problemático, sí lo es el posterior lyyuh/lyyih y su vuelta a un Ella, documentado en época medieval, más próximo al topónimo de época romana ${ }^{10}$.

E. A. Llobregat no dudó en situar Elo en El Monastil, aun sin conocer la existencia de la iglesia situada en la parte alta del yacimiento, basándose en la exis-

y XIV de Toledo el obispo Leander firma únicamente como prelado de la sede ilicitana. En el XV concilio de Toledo un mismo obispo firma como perteneciente a las dos ciudades, es decir como Elicitanae qui et Dotanae sedis; Helicitane; Hilicitanae qui et Dotanae; y las lecturas Eiotane, Elotanae. Acerca de la lectura ecclesiae dotanae no se ha especulado sobre un posible topónimo.

8 A. M. Poveda está realizando un estudio comparativo de las diferentes lecturas aparecidas e los concilios, del que se desprende que tanto la lectura erotanae como dotanae e incluso eiotanae son errores de transcripción. Ver PEIDRO BLANES, Jesús: La región de la Oróspeda..., p. 267, nota 12.

9 VIVES, José: op. cit., p. 409; LLOBREGAT CONESA, Enrique: Los orígenes y el final del obispado...; Ibidem: La primitiva cristiandat...; Ibidem: Las épocas paleocristiana y visigoda...

10 CABEZUELO PLIEGO, José Vicente: Documentos para la historia de Elda. 1356-1370, Ayuntamiento de Elda, Elda, 1991, p. 127 y ss. 
tencia de materiales cristianos pertenecientes o relacionados con este asentamiento. Nos referimos tanto a la tapa de sarcófago con la representación de la escena bíblica de Jonás como a uno de los fragmentos de mesa de altar polilobula$\mathrm{da}^{11}$. Por su parte, A. M. Poveda ha seguido en líneas generales las teorías de E. A. Llobregat, aportando nuevos datos de interés merced a las excavaciones arqueológicas llevadas a cabo desde 1984 en todo el valle de Elda y, en concreto en El Monastil ${ }^{12}$.

Para referirnos al topónimo relativo al hábitat de El Monastil, debemos hacer un pequeño repaso a las fuentes antiguas que mencionan el valle de Elda o el propio yacimiento. Por una parte, en los siglos II-III d.C. el llamado Itinerario de Antonino nombra el sitio de Ad Ello (Itinerario de Antonino 401, 1). En el siglo V d.C., Esteban de Bizancio menciona Ad Elle $e^{13}$. El Anónimo de Rávena, por su parte, (siglos VII-VIII d.C.) cita la población de Edelle o Eloe, según versiones (IV, $42(304,11)$ y V 3 $(343,3))$. Y finalmente, la Guidonis Geographica $(82(515,10))$ presenta el topónimo

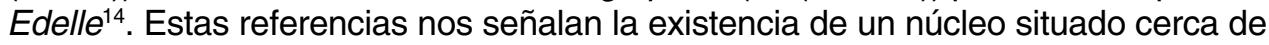
la vía Augusta de la que, no obstante, se debe desviar una distancia no establecida en la cita, puesto que en todos los casos se refiere a un Ad Ello, Ad Elle o Edelle. Es decir, ad supone una preposición que indica dirección ${ }^{15}$, con lo cual el nombre de la ciudad sería Ello. Las lecturas Elle o Eloe parecen, a primera vista, malas interpretaciones o deformaciones del topónimo por parte de los autores. Posiblemente, el Itinerario de Antonino junto con el Anónimo de Rávena, sean las referencias más interesantes. En el caso del primero por ser la más antigua. En este sentido, no parece haber dudas y está plenamente aceptado que Ello se corresponde con el yacimiento de El Monastil. Por tanto, sabemos que en los siglos II-III d.C., existe un topónimo, el de Ello, que posteriormente fue leído de forma diferente por los diversos autores que se refieren al recorrido de la vía Augusta (Tabla 2).

11 LLOBREGAT CONESA, Enrique: Teodomiro...; Ibidem: La primitiva cristiandat...; Ibidem: El altar paleocristiano...; Ibidem: Las sedes episcopales valencianas...; Ibidem: Un sarcófago cristiano...; Ibidem: Relectura del Ravennate...; Ibidem: Las épocas paleocristiana y visigoda..

12 Los resultados de las excavaciones llevadas a cabo han tenido reflejo en múltiples trabajos que se ocupan de la época romana y tardoantigua en el valle de Elda, POVEDA NAVARRO, Antonio: El poblado ibero-romano...; Ibidem: La Sede Episcopal...; Ibidem: La creación de la sede de Elo en la expansión...; Ibidem: Transformación y romanización...; Ibidem: La estructura territorial...; Ibidem: El Monastil: del oppidum ibérico...; Ibidem: La creación de la Sede de Elo en la frontera visigodo-bizantina», Actas de las Jornadas «La Sede de Elo 1400 años de su fundación. El espacio religioso y profano en los territorios urbanos de occidente (siglos V-VII), Elda, 22-24 de abril de 1991, Elda, 1996, pp. 113-136; Ibidem: "La necrópolis del camino de El Monastil (Elda, Alicante)», Actas de las Jornadas "La Sede de Elo 1400 años de su fundación. El espacio religioso y profano en los territorios urbanos de occidente (siglos V-VII), Elda, 22-24 de abril de 1991, Elda, 1996, pp. 351-373; Ibidem: El obispado de Elo...; Ibidem: «Arquitectura sacra de la Carthaginiensis Oriental durante la Antigüedad Tardía: las aportaciones de La Alcudia (Elche) y El Monastil (Elda)», Actas do III Congresso de Arqueologia Peninsular, vol. VI, Porto, pp. 569-579; Ibidem: La iglesia paleocristiana...; Ibidem: «La cristianización del Valle de Elda. Épocas tardorromana y bizantino-visigoda», Historia de Elda, vol. I, Elda, pp. 97-117; Ibidem: «Reorganización episcopal visigoda en el sureste hispano de finales del siglo VI. La creación y localización de la sede de Elo», en prensa.

13 POVEDA NAVARRO, Antonio: Transformación y romanización..., p. 68.

14 ROLDÁN HERVÁS, José Manuel: Itineraria Hispana, Valladolid, pp. 52, 141 y 209-210.

15 ROLDÁN HERVÁS, José Manuel: «Sobre los acusativos con «ad» en el itinerario de Antonino», Zephyrus, XVIII, Salamanca, 1966. 
La política adminstrativo-religiosa del estado visigodo en el Sureste...

Tabla 2. Variantes de la mansio Ad Ello en los itinerarios de época clásica.

\begin{tabular}{|c|c|c|c|}
\hline $\begin{array}{c}\text { Itinerario } \\
\text { de Antonino } \\
\text { (siglos II-III d.C.) }\end{array}$ & $\begin{array}{c}\text { Esteban } \\
\text { de Bizancio } \\
\text { (siglo V d.C.) }\end{array}$ & $\begin{array}{c}\text { Anónimo } \\
\text { de Rávena } \\
\text { (siglos VII-VIII d.C.) }\end{array}$ & $\begin{array}{c}\text { Geografía } \\
\text { de Guido } \\
\text { (siglo XII d.C.) }\end{array}$ \\
\hline Ad Ello & Ad Elle & Edell /Eloe & Edelle \\
\hline
\end{tabular}

(Elaboración propia a partir de Roldán Hervás, José Manuel, Itineraria Hispana, Valladolid).

Por su parte, el Anónimo de Rávena resulta de un mayor interés, puesto que se trata de un texto contemporáneo a la creación de la sede episcopal elotana/eiotana. Debemos atender a la doble lectura que se hace en este texto del nombre de El Monastil, es decir, Elle o Eloe. Lo más interesante de esta disparidad de lecturas es que, mientras la primera refleja una doble «l», manteniendo la lectura señalada en el resto de fuentes, en la segunda aparece Eloe, manteniendo la «-o» de Ello, que se había transformado en «-e» en el resto de fuentes. Si revisamos el resto de ciudades que mencionan estos itinerarios, veremos que a la ciudad de llici, en algunos casos es llamada Illice, con lo cual puede observarse una clara tendencia a la terminación en «-e» de los topónimos. Resulta muy interesante la ambigüedad con la que se escriben los nombres de las ciudades en estas fuentes. En el Anónimo de Rávena, en el que aparece mencionada la ciudad de llici como Illice, observamos dos elementos que se repiten en el caso de la lectura Ello. A saber: en primer lugar, la terminación de ambos topónimos en «-e» y no en «-o», como está reflejado en el Itinerario de Antonino; por otra parte, a diferencia de la grafía habitual de Ilici con una sola «|», en este caso aparece escrito como Illice, esto es, con doble «|», del mismo modo que Ello aparece como Edelle y como Eloe. Por tanto, no sólo estaría documentado el topónimo ad Ello, sino que podría leerse igualmente Eloe y, por tanto, Elo, en momentos cercanos a la creación de la sede episcopal.

Consideramos que es importante no pasar por alto esta doble grafía. Si recordamos los planteamientos de R. Pocklington, este autor otorga gran importancia desde el punto de vista filológico a la dicotomía Ello/Elo para cuestionar la identificación de la ciudad episcopal en el yacimiento de El Monastil ${ }^{16}$.

16 POCKLINGTON, Robert: «El emplazamiento de Iyi(h)», Sharq Al-Andalus, 4, 1987, pp. 175-198. En efecto, señala que la reducción correcta del topónimo a partir de la referencia del Itinerario de Antonino sería de Ello en época romana y Ella* o Ello* en época islámica (leyendo la doble "ele», esto es $\left.|\mathrm{e} / \cdot| \mathrm{la} /{ }^{*}, / \mathrm{e} / \cdot / \mathrm{l} /{ }^{*}\right)$, ya que el autor considera que la presencia de una doble «ele» implica una variación fonética que en esta época sería significativa. Es decir, que la duplicación en la pronunciación de la consonante palatal debería ser tan evidente que quedaría reflejada en la ortografía. Así, en época visigoda, el yacimiento de El Monastil no se llamaría Elo, sino Ello, del mismo modo que se llamaba en el Alto Imperio, perviviendo la doble consonante. Esta duplicación de la palatal se conservaría en época islámica, de forma que el nombre de la ciudad sería Ello* o Ella (por un fenómeno de feminización de los topónimos en árabe). El primer topónimo se basa en una suposición del autor, sin que se haya documentado para esa época, mientras que el segundo aparece en los textos de época bajomedieval, ver CABEZUELO PLIEGO, José Vicente: op. cit., p. 39. Por ello, después de la conquista cristiana, los nombres que aparecen en los textos son los de Ecla, Ella o Etla y Elda, que implican una duplicación de la palatal, con lo que la pronunciación que encontramos en época romana se perpetuaría durante un milenio, según esta hipótesis. 
No obstante, la teoría de R. Pocklington plantea problemas. La ciudad de Ilici no posee en el Anónimo de Rávena una grafía idéntica a la que aparece en otros itinerarios y que es la comúnmente aceptada, ya que aparece como Illice. Si obviamos la «e» final, apreciaremos que el topónimo aparece escrito con doble «l». Aplicando la teoría de R. Pocklington al caso ilicitano, deberíamos postular tres argumentos. Siendo rigurosos con sus planteamientos, estaríamos hablando de otra ciudad, la ciudad de Illice, lo cual parece bastante improbable. Podríamos plantear la posibilidad de que el topónimo se pronunciase indistintamente con la consonante simple o doble. Cabría una tercera opción, esto es, que simplemente el topónimo está mal escrito. Si aceptamos tanto la segunda como la tercera, se abren nuevos caminos a la hora de esclarecer el topónimo de El Monastil en época tardoantigua.

En este punto, la dicotomía Edelle/Eloe podría estar reflejando una doble pronunciación. Igualmente, Edelle sería simplemente una deformación de Ad Ello en la copia de un manuscrito. Si relacionamos esta mala lectura con la existencia del topónimo Illice, es plausible que el copista simplemente leyera mal los topónimos, cometiendo un mismo fallo en ambos.

Sin embargo, Eloe, que también aparece con «e» final, nos plantea nuevos interrogantes. Parece un nuevo error en la escritura, pero al contrario que Edelle, está escrito con una sola «»». Desde nuestro punto de vista, esto debe ponerse en relación con una posible pronunciación del topónimo con una sola «»», esto es, Elo. El hecho de que en la forma Eloe no aparezca reflejada la partícula de dirección "ad», reafirma la hipótesis de que no se trata de un topónimo que ha sido corrompido en la transcripción. En todo caso, parece claro que el nombre de la ciudad de la que hablan los textos puede oscilar entre Ello/Elo (eliminando la «e» final de Eloe). De este modo, la variación Ello/Elo, sería más que plausible en cinco siglos de diferencia entre la referencia del Itinerario de Antonino y el sínodo de Gundemaro ${ }^{17}$.

Siguiendo la secuencia diacrónica, el topónimo Elo pasaría a Ela* o Ella* en época islámica, por la feminización de los topónimos en árabe, bien documentada en otros $\operatorname{casos}^{18}$. Si aceptamos el posible topónimo Ella*, se vuelve a producir la presencia de la consonante doble «|», de manera que se pronunciaría una «|» doble como ya sucedía en época altoimperial, con Ello. Sin embargo, situando Elo en El Monastil, observamos que en el siglo VII ya se habría producido la simplificación de esa consonante doble. En todo caso, parece que en algún momento entre el siglo VII y la Baja Edad Media debió producirse de nuevo la duplicación de la consonante, puesto que está documentada la presencia del topónimo Ella, Ecla o Etla19.

17 POVEDA NAVARRO, Antonio: La creación de la sede de Elo en la expansión...; Ibidem: El Monastil: de oppidum ibérico...; Ibidem: La creación de la sede de Elo en la frontera...; Ibidem: El obispado de Elo...; Ibidem: La iglesia paleocristiana...; MÁRQUEZ, Juan Carlos y POVEDA, Antonio: Espacio religioso y cultura material en Elo...; PEIDRO BLANES, Jesús: La Tardoantigüedad en el Valle de Elda: las cerámicas de El Monastil (siglos V-VIII d.C.), Memoria de Licenciatura, inédito.

18 LLOBREGAT CONESA, Enrique: La primitiva cristiandat...

19 CABEZUELO PLIEGO, José Vicente: op. cit., p. 39, nota 1. Como es bien sabido, en catalán la grafía «t $\mid$ » entre consonantes se lee como una doble «|», esto es, como la actual «/geminada», valga como 
Otro elemento importante a valorar, que en tantas ocasiones han reflejado tanto E. A. Llobregat como A. M. Poveda, es la posibilidad de que El Monastil en época islámica fuera llamado al-munastir, esto es, un lugar de culto fortificado. Esta denominación ha llevado a estos autores a plantear que El Monastil se hubiera convertido en un monasterio en un momento impreciso del siglo $\mathrm{VII}^{20}$. En este sentido, hay que recordar que el canon IV del III Concilio de Toledo permitía que un obispo convirtiera una iglesia de su diócesis en monasterio ${ }^{21}$. Si aceptamos que se convirtió en un monasterio, tal vez se pudiera relacionar con el mantenimiento de la doble nomenclatura de los obispos de la sede con posterioridad a Sanabilis (Tabla 1).

\section{EL MONASTIL EN ÉPOCA BIZANTINA Y VISIGODA A LA LUZ DE LAS FUENTES ARQUEOLÓGICAS}

Desde el punto de vista arqueológico, todo parece indicar que El Monastil sufrió una importante crisis desde mediados del siglo VII, tal como hemos podido documentar con el estudio de la cerámica y que se refleja en un abandono parcial de la parte alta del yacimiento ${ }^{22}$. No obstante, los datos aportados por las excavaciones arqueológicas, ofrecen una nueva visión de la parte alta del asentamiento.

La calle central sufrió remodelaciones en algún momento del siglo VI-VII, reformándose parte de las viviendas de dicha área y cerrándose la misma mediante la construcción de una puerta en la propia calle, que parece delimitar un nuevo espacio. Se construyeron unos muros adosados a las fachadas de las viviendas que se orientan hacia la calle central, de manera que se produjo un estrechamiento en la misma. Se ha interpretado como una puerta que delimita una acrópolis, que estaría amurallada en algunos puntos, separando la parte oeste de la zona alta del yacimiento, de manera que quedaría aislada del resto ${ }^{23}$. Sin em-

ejemplo actual el topónimo Novetlé, que se pronuncia en catalán /novel/lé/. De esta manera, el topónimo medieval Ella al igual que Etla, en realidad se pronunciaría /el/la/, y no /eya/ o /etla/» (con el sonido palatal «elle» del castellano o diferenciando la pronunciación de la «t» y la «l»). El topónimo actual Elda, es el resultado de la dentalización del sonido «|.|/», con lo cual, se produce el sonido «d» tras la «|», que es el que pronunciamos actualmente, ver en PEIDRO BLANES, Jesús: La Tardoantigüedad..., p. 168 y ss.

20 LLOBREGAT CONESA, Enrique: Teodomiro..., p. 49; Ibidem: El altar paleocristiano...; Ibidem: Las épocas paleocristiana..., p. 390; POVEDA NAVARRO, Antonio: La Sede Episcopal Visigoda..., p. 21; Ibidem: La iglesia paleocristiana..., p. 122; Ibidem: «De monasterium visigodo a al-munastir islámico. El Monastil (Elda, Alicante) durante la Alta Edad Media", Monasteria et territoria. Elites, edilicia y territorio en el Mediterráneo medieval (siglos V-XI), Madrid, 2007, pp. 181-201.

21 "...ut liceat episcopo unam ex parrociis basilicam monasterium facere» o bien "ut episcopo liceat unam de parrocitanis ecclesiis monasterium facere...", ver en VIVES, José: op. cit., p. 126; MARTíNEZ, Gonzalo y RODRÍGUEZ, Félix: La Colección Canónica Hispana, V..., pp. 104 y 106; PEIDRO BLANES, Jesús: El valle de Elda..., p. 93.

${ }_{22}$ Los resultados del estudio de los materiales de época tardoantigua pueden consultarse en POVEDA, Antonio, y PEIDRO, Jesús: «Cerámicas tardorromanas y altomedievales en El Monastil (Ello), Elda, Alicante», Estudios de cerámica tardorromana y altomedieval, Granada, 2005, pp. 341-375; así como en PEIDRO BLANES, Jesús: La Tardoantigüedad...; además, sobre la menor presencia de materiales ver PEIDRO BLANES, Jesús: El valle de Elda, de los romanos..., p. 93.

${ }^{23}$ Comunicación personal de A. M. Poveda, al cual agradecemos este dato. 
bargo, no podemos olvidar que la calle central tiene una bifurcación más al oeste de donde encontramos la supuesta puerta. En el caso de admitir que se esté delimitando este nuevo espacio incluyendo en él la zona de la calle bifurcada, se trataría de una zona de grandes dimensiones, separada del resto del asentamiento. La calle central en su lado oeste, esto es, el sector que abarca este nuevo espacio, parece corresponder a la de mayor representatividad tanto política como administrativa y religiosa de la ciudad. Es más, en la parte más alta del yacimiento se levanta la iglesia, que ha sido ampliamente estudiada por A. M. Poveda ${ }^{24}$. Es de una sola nave, de planta rectangular y con ábside en el lado este, datada entre los siglos VI-VII25. Los pies están orientados al oeste, es decir, se trata del lugar más alejado respecto al núcleo habitado, mientras que se le adosa en su lado sur una estancia rectangular en forma de cuña, donde se encuentra una piscina bautismal muy rústica, una fosa de forma pentagonal excavada en la roca, con dos peldaños labrados. La situación de la iglesia en la parte más alta del cerro, así como la ausencia de construcciones aledañas, permitía que fuese un edificio perfectamente visible desde prácticamente cualquier punto del asentamiento y del valle. Sin duda su ubicación responde a la voluntad de situar un edificio de su importancia en un lugar privilegiado y al que sólo podían acceder las clases altas de la comunidad.

Asociados al templo cristiano se han documentado tanto elementos arquitectónicos, como administrativos y religiosos. Se trata de diferentes fragmentos de celosías o canceles, ajimeces, una basa de columna octogonal, varios fragmentos de una mesa de altar, algunos ponderales bizantinos, una píxide de marfil, una cucharilla de bronce igualmente bizantinas y una pieza cerámica interpretada como de uso litúrgico 26 .

En cualquier caso, a pesar de que no podemos considerar El Monastil como un núcleo urbano desde el punto de vista morfológico, sí debemos señalarlo como un asentamiento que jugó el papel reservado a la ciudad, como administrador y ver-

24 POVEDA NAVARRO, Antonio: El obispado de Elo...; Ibidem: Arquitectura sacra...; La iglesia paleocristiana...; MÁRQUEZ, Juan Carlos y POVEDA, Antonio: Espacio religioso y cultura material en Elo...; POVEDA, Antonio, MÁRQUEZ, Juan Carlos y PEIDRO, Jesús.: «La iglesia paleocristiana de El Monastil (Elda, Alicante) y su contexto arqueológico y urbano (siglos V-VII d.C.)», Actas del XV Congreso Internacional de Arqueología Cristiana "Episcopus, ciuitas, territorium». Toledo 8-12 septiembre de 2008, en prensa.

${ }_{25}$ POVEDA NAVARRO, Antonio: Arquitectura sacra...; POVEDA, Antonio, MÁRQUEZ, Juan Carlos y PEIDRO, Jesús: op. cit.

${ }^{26}$ Para la columna, ver POVEDA NAVARRO, Antonio: Arquitectura sacra...; Ibidem: La iglesia paleocristiana...; una primera aproximación a la mesa de altar en LLOBREGAT CONESA, Enrique: El altar paleocristiano...; un estudio completo en MÁRQUEZ VILLORA, Juan Carlos: «Comercio oriental y culto cristiano en el Valle del Vinalopó: la mesa polilobulada de El Monastil (Elda, Alicante)», Alebus, 4-5, 19941995, pp. 109-128; Ibidem: «Mesas polilobuladas...; MÁRQUEZ, Juan Carlos y POVEDA, Antonio: «Espacio religioso y cultura material en Elo; Ibidem: «Espacio religioso y cultura material en Ilici (siglos IVVII d.C.)", V Reunió d'Arqueologia Cristiana Hispànica, Cartagena (1998), Barcelona, 2000, pp. 185-198. Para los ponderales, la pyxide y la cucharilla, ver POVEDA NAVARRO, Antonio: La iglesia paleocristiana..., pp. 121-122. Para la pieza cerámica NAVARRO PASTOR, Alberto: Historia de Elda, vol. I, Diputación Provincial, Alicante, 1981, especialmente pp. 50 y 59; así como POVEDA NAVARRO, Antonio: $L a$ iglesia paleocristiana..., p. 120. 
La política adminstrativo-religiosa del estado visigodo en el Sureste...

tebrador del territorio, abandonando la idea de que se trata de un «pequeño asentamiento de altura», opinión que en absoluto compartimos ${ }^{27}$.

\section{LA CREACIÓN DE LAS SEDES EPISCOPALES DE BEGASTRI $Y$ ELO: UNA NUEVA PROPUESTA A PARTIR DE LAS ACTAS DE LOS CONCILIOS TOLEDANOS}

Tradicionalmente se ha situado la creación de las nuevas sedes de Begastri y Elo entre los años 589 y $610^{28}$, entre la celebración del III Concilio de Toledo y el Decreto de Gundemaro, que aparece anejo a las actas del XII Concilio de Toledo, fechado en el año $681^{29}$. En el III Concilio de Toledo tampoco aparecen las sedes de Ilici y Carthago Spartaria, lo que se ha interpretado como la prueba de que se encontrarían bajo control imperial, incluso ostentando carácter episcopal dentro de la administración bizantina. Por esta razón se crearían en un momento indeterminado entre las fechas referidas las sedes de Elo y Begastri, que vendrían a sustituir a aquéllas.

En el Decreto de Gundemaro se reconoce la preeminencia de Toledo frente a la de Carthago Spartaria con respecto a la provincia Carthaginense. Para ello firman el texto en primer lugar los obispos de todas las diócesis hispanas excepto los de la Carthaginense, que lo hacen tras responder al decreto real, acatándolo. En total, son quince los obispos de la Carthaginense los que aparecen en las actas. Sabemos que no necesariamente se trata del total de prelados existentes en la provincia, ya que son muchos los casos de ausencias en los concilios por múltiples

27 GUTIÉRREZ, Sonia, ABAD, Lorenzo y GAMO, Blanca: Eio, lyyuh y el Tolmo..., p. 364; POVEDA, Antonio, MÁRQUEZ, Juan Carlos y PEIDRO, Jesús, op. cit.; PEIDRO BLANES, Jesús: El valle de Elda, de los romanos..., pp. 93-95.

${ }_{28}$ Son muchos los autores que señalan una fecha cercana al 590 para la creación de ambas sedes VIVES, José: op. cit., pp. 4-7; PALOL, DE, Pere: Arqueología cristiana de la España Romana. Siglos IVVI. I. Monumentos, Madrid-Valladolid, 1967; LLOBREGAT CONESA, Enrique: Las sedes episcopales valencianas..., pp. 403-404; BELTRÁN TORREIRA, Federico: «El conflicto por la primacía eclesiástica de la Cartaginense y el III Concilio de Toledo", XIV Centenario del III Concilio de Toledo, Toledo, 1991, pp. 497-510; VALLEJO GIRVÉS, Margarita: op. cit., p. 242; POVEDA NAVARRO, Antonio: La creación de la sede de Elo en la frontera..., pp. 115-116; ABAD, Lorenzo, GUTIÉRREZ, Sonia y GAMO, Blanca: La basílica y el baptisterio..., p. 111. E. A. Llobregat con posterioridad se ha desmarcado de esta datación, inclinándose por una fecha más tardía, cercana al 610, LLOBREGAT CONESA, Enrique: Las épocas paleocristiana..., pp. 396-399. Por otra parte, A. Fernández Guerra situaba la creación de las sedes en momentos anteriores, de forma que la firma en el sínodo de Gundemaro implicaba un avance visigodo importante FERNÁNDEZ GUERRA, Antonio: op. cit., pp. 20-22. EI P. Flórez, a su vez, señala que se trata de dos sedes que sustituyen a las de llici y Carthago Spartaria, sin embargo, no hace ningún tipo de reflexión acerca de la cuestión cronológica sobre su fundación, FLÓREZ, Enrique: España Sagrada, Vol. VII, Madrid. 1751, especialmente p. 125.

${ }_{29}$ A. González Blanco ha manifestado sus objeciones acerca de la autenticidad de este documento y ha señalado algunas de sus incongruencias y probables faltas de rigor. Aporta, además, una interesante bibliografía sobre el tema, a la cual remitimos, ver GONZÁLEZ BLANCO, Antonino: «La historia del S.E. peninsular entre los siglos III-VIII d.C. Fuentes literarias, problemas y sugerencias", Antigüedad y Cristianismo, II, 1985, pp. 53-79, 1985, destacando las pp. 69-73; Ibidem: «El Decreto de Gundemaro y la historia del siglo VII», Antigüedad y Cristianismo, III, 1986, pp. 159-169, con especial atención a la p. 161 y ss.). 
factores. Si tenemos en cuenta que las firmas se realizan por orden de antigüedad del obispo y no tanto de la silla episcopal, podemos conocer en qué orden fueron nombrados los prelados que aparecen en la firma del Decreto.

\subsection{El Decreto de Gundemaro: comentarios a la precisión en el listado de firmas episcopales}

A pesar de ello, no podemos pasar por alto las objeciones planteadas por A. González Blanco al texto del Decreto de Gundemaro ${ }^{30}$. Según este autor se trataría de un documento falso, redactado en el contexto político-religioso del XII Concilio de Toledo, en el que aparece como anejo. Todo parece indicar que en el marco de un deseo centralizador del Estado visigodo en torno a la ciudad de Toledo se redactó el Decreto que reconocía la preeminencia de Toletum frente a Carthago Spartaria. Entre las razones que se exponen para demostrar la falsedad del documento destaca que Carthago Spartaria en tiempos de Gundemaro se encontraba en manos bizantinas, lo cual implicaría un conflicto entre dos estados. De este modo, según A. González Blanco, no tendría sentido que Toledo se planteara cuestiones relativas a las competencias religiosas de ambas ciudades, puesto que no le correspondería el territorio dominado en esos momentos por los imperiales. Por el contrario, cobraría sentido en un contexto en el que Carthago Spartaria había sido ya conquistada por los visigodos y se planteaba un problema administrativo-religioso que el Decreto de Gundemaro trataba de resolver a favor de Toledo ${ }^{31}$.

Independientemente de la autenticidad del documento, lo que nos interesa en este trabajo es la veracidad de los datos que aporta en cuanto a las firmas episcopales. En este sentido, debemos preguntarnos hasta qué punto pudo ser manipulado el texto. Siguiendo nuevamente las afirmaciones de A. González Blanco, observamos la firma de dos obispos de Cástulo. Por una parte, Venerius ecclesiae Castulonensis episcopus en el decreto real y por otra Theodorus sanctae ecclesiae

\footnotetext{
30 Algunas de las incongruencias que señala el autor, no obstante, se basan en criterios subjetivos, como la longevidad de algunos obispos, que en el caso de Eterius de Basti considera «...un milagro del cielo...". Desde nuestro punto de vista, no hay razón objetiva para dudar que un obispo pudiera permanecer 35 años en el cargo como sería este caso, o los 28 años de lacobus de Mentesa, GONZÁLEZ BLANCO, Antonino: La historia del S.E. peninsular..., p. 71. Una prueba de que no necesariamente se trata de un mismo obispo la encontramos en lohannes ecclesiae Egabrensis episcopus... que estampa su firma en segundo lugar tras el metropolitano de Sevilla en el concilio provincial celebrado en la capital hispalense en el año 590, lo cual significa que es el obispo más veterano y tiene el honor de firmar justo por detrás del obispo de Sevilla, Leandro. En las actas del II Concilio de Sevilla, del año 619 vuelve a aparecer un obispo de la iglesia egabrense llamado lohannes, que no puede tratarse del mismo, ya que en este caso ocupa el quinto lugar por detrás del obispo Isidoro. Así, lohannes tiene por delante a los prelados de Elvira, Asidonia, Astigi e Italica, que en el I Concilio se encontraban por detrás, aparte de no ser los mismos en ambos concilios, lo cual implica que haya nombramientos posteriores al I Concilio. Se confirmaría así que se trata de dos lohannes diferentes porque, en caso contrario, en el II Concilio de Sevilla el obispo egabrense aparecería antes que los citados prelados, VIVES, José: op. cit., pp. 153 y 185.

${ }^{31}$ GONZÁLEZ BLANCO, Antonino: La historia del S. E. peninsular..., pp. 69-73; Ibidem: El Decreto de Gundemaro..., pp. 159-169.
} 
Castolonensis urbis episcopus en la constitución episcopal de la Carthaginense, que son llamados Venerius y Teudorus respectivamente en la nueva edición crítica de los textos. Éste último, Teodoro, aparece igualmente en el III Concilio toledano del 589, por lo que, al menos, el nombre del obispo sería real ${ }^{32}$. No hay constancia documental de la existencia de un obispo de Cástulo llamado Venerius, puesto que es la única vez que aparece en un concilio. En todo caso, aparece en último lugar, como el obispo de más reciente nombramiento, sin que pueda explicarse su aparición en estas firmas.

Para intentar valorar en su justa medida las posibles manipulaciones en los nombres y el orden de los prelados, debemos prestar atención a los diferentes concilios provinciales celebrados entre el III y el IV Concilio de Toledo y contrastar con el listado del Decreto de Gundemaro los datos que ofrecen. Así, la relación de obispos pertenecientes a la Tarraconense sigue un orden bastante lógico en el decreto real si lo comparamos con las lista de firmantes del II Concilio de Barcelona, celebrado en el año 599, con un único desajuste ${ }^{33}$. En el mismo caso nos encontramos

32 VIVES, José: op. cit., pp. 138 y 407-408; GONZÁLEZ BLANCO, Antonino: «La historia del S. E. peninsular..., p. 71; MARTÍNEZ, Gonzalo y RODRÍGUEZ, Félix: La Colección Canónica Hispana, V..., pp. 145,209 y 211.

${ }^{33}$ En efecto, Eusebio aparece en el Decreto de Gundemaro como obispo de Tarragona por detrás del resto de metropolitanos, puesto que sería el último en ser nombrado. En el II Concilio de Barcelona el metropolitano de Tarragona es Asiaticus, por lo que Eusebio debió ser nombrado en un momento posterior al 599. Juan, obispo de Gerona, aparece dos puestos por detrás del tarraconense, mientras que en el concilio barcelonés firma como lohannes peccator de Gerunda in his constitutionibus annuens subscripsi y en el Concilio de Toledo del año 597 ya se tiene constancia de este obispo. En el texto del Decreto, tres puestos por detrás de este Juan aparece Maximus ecclesiae Cesaragustanae, que efectivamente firma un lugar después de Juan en el concilio provincial. No obstante, encontramos un desajuste en el caso del obispo de Calagurris, Munius, que según L. A. García Moreno, fue nombrado sobre el 587, GARCÍA MORENO, Luis: Prosopografía del Reino visigodo de Toledo, Madrid, 1974, p. 208, n. 594. Mientras que en el concilio de Barcelona aparece Munius tres puestos por delante de lohannes y cuatro de Maximus, en el Decreto Munius ecclesiae Calagorritanae episcopus está colocado justo después de Máximo de Zaragoza y cuatro puestos por detrás del obispo de Gerona, VIVES, José: op cit., pp. 157, 160-161 y 406. Leyendo las actas del II Concilio de Zaragoza del año 592, igualmente provincial, en el que no aparece la iglesia a la que pertenece ninguno de los obispos que aceptan las actas, observamos la firma de Mumius in Christi nomine episcopus subscrpsi, tres puestos por delante de lohannes in Christi nomine subscrpsi. Evidentemente se están refiriendo a los mismos Munius y lohannes del II Concilio de Barcelona y del Decreto de Gundemaro, con lo que se confirma que Munius, obispo de Calagurris habría sido nombrado antes que Iohannes de Gerona y que en el Decreto existiría un desajuste en la lista, Idem, pp. $155,160-161$ y 406 . Este hecho se confirma en el concilio provincial de la Tarraconense celebrado en Egara en el año 614, en el que tampoco se refleja la iglesia a la que pertenece cada uno de los prelados, como ya habíamos visto en el caso del II Concilio de Zaragoza. La fórmula Eusebius sub. aparece en primer lugar, en su papel de metropolitano de Tarragona, seguido de un tal Munius, que correspondería al obispo de Calagurris. Detrás de su firma se constata la de lohannes, a todas luces el prelado de la iglesia gerundense. De este modo, insistimos, se confirma que el obispo Munius debió ser nombrado previamente a lohannes de Gerona, tal como recoge L. A. García Moreno, VIVES, José, op. cit., pp. 160-161 y 406; GARCÍA MORENO, Luis: Prosopografía..., pp. 213-214.

Finalmente, destacamos la firma In Christi nomine Ugnas Barcinonensis episcopus hunc consensum subscripsi en el concilio barcelonés del 599, nombrado en momentos anteriores al III Concilio de Toledo GARCÍA MORENO, Luis, idem..., pp. 202-203, mientras que en el Decreto de Gundemaro aparece Emila ecclesiae Barcinonensis episcopus ss., cinco puestos por detrás de Munius de Calagurris y a nueve de lohannes de Gerona, en lógica con el hecho de que habría sido nombrado en un momento indeterminado posterior al 599, ver en VIVES, José, op. cit., pp. 160 y 406. 
con las sedes béticas del Decreto y los obispos nombrados en el II Concilio de Sevilla, del año 619, en el que se percibe otro desajuste en el orden de las firmas ${ }^{34}$.

De la lectura de estos concilios provinciales se desprende que los nombres de los prelados que aparecen en el Decreto y en la posterior constitución de obispos de la Carthaginense son reales, ya que en algún momento estuvieron en posesión de ese cargo. Parece poco probable que si se trata de un documento falsificado en época del XII Concilio de Toledo se inventaran los nombres de los obispos, ya que como indica A. González Blanco «Se escoge el nombre de un rey de poco relieve, ubicado en una época lo suficientemente antigua como para que haga tradición, pero no tan antigua que no pueda compaginar con los documentos conciliares que hay que rebatir...» ${ }^{35}$. Es decir, podría tratarse de un documento falso en cuanto al contenido y a la omisión de algún obispo, pero no parece que se haya producido una manipulación de los nombres ${ }^{36}$ ni de las sedes que aparecen ni de su orden, más allá de algún pequeño desajuste documentado en la firma del Decreto por parte de los obispos de las diócesis hispanas, pero no en el correspondiente a los prelados de la Carthaginense.

\subsection{Los obispados de Vicentius de Begastri y Sanabilis de Elo ${ }^{37}$}

Volviendo a la idea de que los obispos firman las actas por orden de nombramiento y no por la antigüedad de la sede, en la Constitución de los obispos de la Carthaginense, Vicentius, obispo begastrense firma en el puesto undécimo de la lista, mientras que Sanabilis, obispo elotano lo hace el decimoquinto y último. Los datos con que contamos no permiten especificar el tiempo transcurrido entre el

${ }^{34}$ Las actas de esta reunión son muy interesantes por cuanto se datan tan sólo nueve años después de la pretendida fecha de redacción del Decreto de Gundemaro. En ellas encontramos la firma de Fulgentius in Christi nomine ecclesiae Astigitanae episcopus ss., que aparece igualmente en el Decreto de Gundemaro Ego Fulgentius ecclesiae Astigitanae episcopus ss., lo cual no resulta en absoluto problemático. No obstante, encontramos la firma de Pisinnus ecclesiae Eliberritanae episcopus ss. en el antepenúltimo lugar de la lista en el Decreto de Gundemaro, es decir, once puestos por detrás del referido Fulgentius de la sede astigitana, mientras que en el concilio sevillano aparece la firma de un tal Bisinus in Christi nomine ecclesiae Eliberritanae episcopus ss., dos puestos por delante de Fulgentius, VIVES, José: op. cit., pp. 185 y 406-407). Aquí se produciría un nuevo desajuste, ya que todo parece indicar que el Pisinnus del Decreto de Gundemaro y el Bisinus del concilio hispalense son el mismo, de forma que no sería posible el baile de posiciones de una lista a la otra. El obispo de Elvira habría sido nombrado con anterioridad al de la sede astigitana según el concilio sevillano, de forma que existiría un error en el listado que recoge el Decreto de Gundemaro.

35 GONZÁLEZ BLANCO, Antonino: La historia del S. E. peninsular..., p. 73.

${ }^{36}$ Excepto el ya mencionado obispo Venerius de Cástulo, ver en VIVES, José, 1963: 407 y en MARTíNEZ, Gonzalo y RODRÍGUEZ, Félix, 2002: 209.

37 Parte de la argumentación que desarrollamos en este y el siguiente apartado del presente artículo fue expuesta públicamente en el marco del V Seminario Internacional de Historia «Bizancio y el Mediterráneo Occidental entre la Tardoantigüedad y el Medievo", celebrado los días 1 y 2 de diciembre de 2005 en Elda, PEIDRO BLANES, Jesús: «Las sedes episcopales de Begastri y Elo en la frontera visigodo-bizantina", Actas del V Seminario Internacional de Historia. Bizancio y el Mediterráneo occidental entre la Tardoantigüedad y el Medievo, Elda, 1-2 diciembre 2005, Elda, en prensa. Queremos agradecer los comentarios y apreciaciones realizados por $\mathrm{M}$. Vallejo acerca de algunos puntos de nuestro análisis que, de un modo u otro, han sido reflejados en el texto final del trabajo. 
nombramiento de estos obispos, pero indican que Vicentius fue nombrado antes que Sanabilis, ya que entre ambos firman otros tres prelados. Lo cierto es que Sanabilis fue a la reunión siendo el obispo nombrado más recientemente de los asistentes. Esto ha llevado a algunos autores a interpretar que la silla de Elo se creó cerca del 610 , alejándose de quienes propugnan una fecha más temprana, poco después de la pacificación de la Oróspeda y del III Concilio de Toledo ${ }^{38}$.

Las actas de los concilios nos informan de la presencia por primera vez de los obispos de Begastri y Elo, de forma que se ha tendido a considerar que tanto $\mathrm{Vi}$ centius como Sanabilis fueron los primeros prelados que ejercieron su autoridad al frente de dichos episcopados. No obstante, no tenemos la certeza de que eso fuera así. Es posible que tanto Vicentius como Sanabilis tuvieran un antecesor en el cargo, como se ha planteado en alguna ocasión. Se conocen los nombres de Acrisminus y de Vitalis, obispos begastrenses, a partir de sendas inscripciones que A. Fernández Guerra recoge en sus trabajos, pero que no han llegado hasta nosotros, siendo la única fuente con la que contamos la del testimonio del propio Fernández Guerra ${ }^{39}$. De todos modos, en caso de haber existido, estos obispos no deben considerarse necesariamente anteriores a Vicentius, puesto que pudieron haber ostentado el obispado con posterioridad a éste ${ }^{40}$.

Aun así, es posible que, a pesar de que el Decreto de Gundemaro sea la primera referencia documental que tenemos sobre estas sedes episcopales, probablemente, su creación fuera anterior. Es decir, que no necesariamente Vicente y Sanable fueron los primeros obispos nombrados en estas sedes. En este caso, deberíamos señalar que Vicente fue nombrado con anterioridad a Sanable, dado que su predecesor o predecesores desaparecieron antes que el de Sanable. Por tanto, ambas sedes podrían haberse creado en un mismo momento, lo cual iría en consonancia con la teoría clásica que aboga por la creación bajo el reinado de Recaredo. Sin embargo, no tenemos hasta la fecha ningún dato fehaciente que mencione o permita situar la creación de la sede elotana en un momento anterior a Sanabilis.

\subsection{Implicaciones historiográficas de la datación de los obispados de Vicentius de Begastri y Sanabilis de Elo}

Después del análisis de las actas conciliares, podemos señalar que, en el caso de considerar que Vicentius y Sanabilis no fueron los primeros en ocupar las sillas episcopales sino que las sedes fueron creadas con anterioridad, las tesis tradicionales, seguirían en vigor. En este sentido, deberíamos considerar que su creación fue obra de Recaredo y, si no al mismo tiempo, con muy poca diferencia entre una y otra.

\footnotetext{
${ }^{38}$ L. A. García Moreno sitúa el nombramiento de Sanabilis en el 610, GARCíA MORENO, Luis: Prosopografía...

39 GARCÍA MORENO, Luis: Prosopografía..., pp. 126-127.

40 PEIDRO BLANES, Jesús: La región de la Oróspeda..., p. 271.
} 
Por el contrario, si seguimos la hipótesis que considera que fueron ellos los primeros obispos de las sillas begastrense y elotana, debemos hacer una serie de precisiones que consideramos de gran importancia.

Si la creación de la sede de Elo se encuentra íntimamente ligada al obispado de Sanabilis y, por tanto, debe datarse en el año 610, el espacio temporal entre la misma y la pacificación de la Oróspeda resulta muy significativo. Nos moveríamos en un espacio temporal de prácticamente un cuarto de siglo de diferencia entre el final del reinado de Leovigildo ${ }^{41}$ y la creación de las sillas episcopales, de forma que deberíamos descartar la pacificación y administración de la Oróspeda como motivo principal utilizado para la creación de ambas sedes, ya que tanto en el caso de Begastri como en el de Elo, el tiempo transcurrido sería excesivo.

Otro de los discursos tradicionales que deberíamos modificar es el de la autoría de Recaredo para, al menos la sede de Elo. Siguiendo esta argumentación, Recaredo no habría creado las sedes episcopales, si bien pudo haber allanado el camino para que fuera una realidad años después. Las motivaciones que propiciaron la creación de estas nuevas sedes tal vez habría que buscarlas en la situación existente entre visigodos e imperiales. Tras el largo y belicoso reinado de Leovigildo se había conseguido la conquista y pacificación de la Oróspeda. Probablemente ante el avance visigodo y temiendo futuras ofensivas del enemigo, el emperador Mauricio envió a Comenciolo con el fin de asestar el primer golpe. Tal como hemos comentado con anterioridad, todo parece indicar que fue así, de forma que Recaredo se vio obligado a responder las romanas insolentias citadas por Isidoro de Sevilla ${ }^{42}$. En este contexto, no conocemos el alcance de estas operaciones militares, de forma que resulta muy difícil entender cuál sería la situación al final del reinado de Recaredo.

De Liuva II sabemos muy poco, puesto que reinó únicamente dos años, al parecer, sin acciones dignas de ser recogidas por las fuentes escritas del momento. Sin embargo, indican una importante actividad bélica durante el reinado de Witerico, que no habría tenido como reflejo un gran avance del poder visigodo. Las fuentes señalan el interés de Witerico por atacar las posiciones bizantinas, con resultados ciertamente mediocres ${ }^{43}$. El estancamiento del ejército visigodo y el buen

41 Límite máximo en el que podemos incluir la pacificación de la Oróspeda.

42 Para un análisis histórico de esta situación VALLEJO GIRVÉS, Margarita: op. cit., 1993, pp. 239243. Desde una perspectiva más literaria e ideológica se han ocupado otros autores, como es el caso de ZECCHINI, Giuseppe: Ricerche di storiografia latina tardoantica, 1993, Roma; FONTAINE, Jacques: «Isidoro de Sevilla frente a la España bizantina», V Reunió d'Arqueologia Cristiana Hispànica, Cartagena (1998), 2000, pp. 29-39; Ibidem: Isidoro de Sevilla. Génesis y originalidad de la cultura hispánica en tiempos de los visigodos, Madrid, 2002 (ed. francesa [2000]).

43 VALLEJO GIRVÉS, Margarita: op. cit., pp. 265-268. Desde el punto de vista de nuestra investigación debemos lamentar el vacío historiográfico existente entre la celebración del III Concilio y el advenimiento de Sisebuto al trono de Toledo. Juan de Biclaro termina su relato tras el III Concilio, mientras que Isidoro de Sevilla comienza con Recaredo, sin embargo, pasa por alto los reinados de Liuva II y Witerico, para centrarse posteriormente en el de Sisebuto, con el que el obispo sevillano mantuvo una excelente relación. En este sentido, el hecho de que Isidoro no se detenga en la narración de los acontecimientos ocurridos durante un periodo de diez años, en los reinados antes mencionados, debe ponerse en relación en el caso de Liuva II por lo corto del mismo, apenas dos años, mientras que en el caso de 
estado de las defensas imperiales tal vez impulsó a Witerico a la creación de las nuevas sedes episcopales de Begastri y Elo con el fin de establecerlas en la línea de frontera que no habría sido capaz de sobrepasar con sus campañas militares. En este contexto sería factible que la necesidad de establecer una frontera con los bizantinos fuera necesaria o incluso apremiante, ya que Witerico debería asegurar una frontera con los territorios imperiales tras el fracaso de su eventual ofensiva militar. La línea que se dibujaría en estos momentos estaría próxima a la ciudad de Ili$c i$, tal como se ha situado durante el reinado de Sisebuto ${ }^{44}$. En la parte más próxima a Carthago Spartaria, con toda seguridad se situaría más al sur de Begastri. De este modo, podemos plantear que las sedes episcopales de Elo y Begastri se encontrarían, efectivamente, cercanas a los límites controlados por los bizantinos y no en el intrapaís, como se ha sugerido en otras ocasiones ${ }^{45}$. Asimismo, siguiendo esta línea argumental, a pesar de que las sedes de Begastri y Elo serían creadas bajo un mismo monarca, posiblemente lo fueron en momentos diferentes, que habría que relacionar con el desigual avance visigodo en la zona murciana y alicantina.

Por tanto, a la luz de esta hipótesis, la creación de la sede de Elo posiblemente en un momento indeterminado del reinado de Witerico, en general, o en el año 610 en particular, podría explicar su ubicación en El Monastil. Una creación tardía de la sede elotana invalidaría, a nuestro entender la posibilidad de que Elo se encontrase en El Tolmo de Minateda, puesto que perdería sentido que se tratase de una creación que tuviera como fin controlar la región de la Oróspeda y, sin embargo, se crease más de veinte años después de la campaña de Leovigildo en esta zona ${ }^{46}$. Por el contrario, desde nuestro punto de vista, cobraría más fuerza la idea de la creación de una sede situada en torno a la frontera con los bizantinos, tras varias campañas ofensivas por parte del Estado visigodo. En este sentido, no podemos admitir la hipótesis que aboga por que la necesidad de administrar los territorios de

Witerico parece relacionarse con motivaciones ideológicas. La llegada al trono de Witerico viene precedida de una conspiración contra Liuva II, que termina con su vida poco después. Puesto que Isidoro se sentía de algún modo ligado a la estirpe de Recaredo (recordemos que se convierte al cristianismo, lo cual es ensalzado por Isidoro), la usurpación de Witerico no sería vista con buenos ojos por el obispo sevillano, que habría preferido ignorar el papel del rey, ZECCHINI, Giuseppe, op. cit;; FONTAINE, Jacques: Isidoro de Sevilla. Génesis y originalidad... Lo que conocemos de Witerico, aparte de la forma en la que subió al trono y de que fue asesinado, es que realizó algunas campañas militares contra los bizantinos, si bien con resultados más bien modestos, según el propio Isidoro. No obstante, la relación de estos hechos no puede esconder la ideología de Isidoro, claramente enfrentado a Witerico. Llama la atención que las campañas de Sisebuto, tan alabado por el sevillano, tuvieron un resultado bastante más positivo. Cabe la posibilidad de que dicho enfrentamiento ideológico haya sesgado de algún modo la información facilitada por Isidoro. No obstante, con los datos que poseemos en estos momentos, resulta evidente que durante el reinado de Witerico se produjeron algunas campañas militares que no tuvieron un gran éxito. Éstas suelen situarse en la Bética, pero debemos recordar que Isidoro, nuestra única fuente en este caso, se centra normalmente en los hechos acaecidos en esta parte de la Península, VALLEJO GIRVÉS, Margarita: op. cit., p. 265 y ss. Por ello, las operaciones militares emprendidas por Witerico podrían haber afectado, en general, a los dominios imperiales peninsulares.

44 VALLEJO GIRVÉS, Margarita: op. cit.

45 ABAD, Lorenzo, GUTIÉRREZ, Sonia y GAMO, Blanca: La basílica y el baptisterio del Tolmo...; GUTIÉRREZ LLORET, Sonia: La identificación de Madinat lyih...

${ }_{46}$ Para una interpretación de la administración de la Oróspeda a finales del siglo VI, ver PEIDRO BLANES, Jesús: La región de la Oróspeda... 
la Oróspeda fuera apremiante, si bien el avance visigodo posterior hizo patente durante el reinado de Witerico la necesidad de establecer un control administrativo más directo. De este modo, siempre en el terreno de la hipótesis, podríamos plantear que los territorios conquistados a los bizantinos serían administrados por otras sedes, que no podrían hacerse cargo debidamente, lo cual pudo impulsar a Witerico a crear estas sedes. 